\title{
Transposition Surgery in Childhood Strabismus
}

\author{
H. E. WILLSHAW and G. M. O'CONNOR \\ Birmingham
}

\begin{abstract}
Summary
Transposition surgery involves an alteration in the mechanical properties of muscle action, such that the direction of movement of the eye following contraction of the muscle is modified. Though often used in the management of more complex motility disorders we have investigated the role of such surgery in concomitant childhood strabismus, and report the results of a computer model prediction and a retrospective review of cases.
\end{abstract}

Transposition surgery differs in essence from other forms of strabismus surgery, in that it's intention is not to increase or decrease the force of contraction of a muscle, but rather to modify the effect on ocular rotation when that muscle is called into action. Obviously transpositions may be combined with recessions or resections, but it is the modified direction of pull that is the hallmark of the transposition procedure.

Many of the better known transposition procedures are used to deal with persistent defects of ocular rotation, such as the Jensen operation for lateral rectus palsy, ${ }^{1}$ in which slips of the superior and inferior rectus are attached to the corresponding halves of the lateral rectus. Though abduction remains very limited after such a manoeuvre, the transposition exerts a mechanical effect, tethering the eye laterally, and resisting the adducting force of a relatively hypertonic medial rectus. Any restoration of abduction presumably reflects persisting activity in the 'paretic' muscle. The Harada-Ito operation ${ }^{2}$ is used to increase the intorsional force in superior oblique weakness, particularly in bilateral cases where torsional diplopia is a major complaint. The Knapp procedure ${ }^{3}$ has been widely used to elevate hypotropic eyes, and may be particularly useful when such hypotropia is associ- ated with defective elevation and ptosis. Lee and Collin have reported 12 such cases ${ }^{4}$ and found that whilst correction of the hypotropia was often limited, restoring some Bell's phenomenon was useful when considering later ptosis surgery.

Transposition of the superior oblique tendon for adduction weakness, ${ }^{5}$ transposition of the inferior oblique tendon for inferior oblique overaction ${ }^{6}$ and several other operative procedures ${ }^{7,8}$ have been described, and all share the essentially mechanical nature of their effect. Because of this one would anticipate that computer models of muscle action, based on mechanical principles, would predict accurately the effect of such surgery. We have been fortunate to have access to the computer model designed by Dr Richard Clement ${ }^{9}$ which has previously demonstrated its value in a study of ' $A$ ' and ' $V$ ' phenomena, ${ }^{10}$. and using this model we have compared our results in a series of patients with the result predicted by the computer model.

\section{Material and Methods}

Run on the ICL 1904S computer at Aston University the model was asked two questions. Firstly, what is the effect of transposing the insertion of each horizontal rectus muscle of one eye either upwards or downwards by 
Table I Analysis of 34 patients reviewed

\begin{tabular}{lccc}
\hline & Age at surgery & Follow up & Horizontal deviation \\
\hline Hypertropia/hypotropia & $8 \mathrm{yr} 4 \mathrm{mth}$ & $16.6 \mathrm{mth}$ & 10 Exotropia \\
& $(2.1-15.1)$ & $(1-52)$ & 6 Esotropia \\
Vertical incomitance & $7 \mathrm{yr} 4 \mathrm{mth}$ & $13.6 \mathrm{mth}$ & 9 Exotropia \\
& $(3.1-13.3)$ & $(0.5-66)$ & 9 Esotropia \\
\hline
\end{tabular}

$10 \mathrm{~mm}$. Secondly the computer was asked to model each of the manoeuvres we have regularly used for dealing with ' $\mathrm{A}$ ' or ' $\mathrm{V}$ ' phenomena in the absence of oblique muscle dysfunction, that is:

'A' esotropia—elevate each medial rectus, or elevate medial rectus, depress ipsilateral lateral rectus

' $V$ ' esotropia-depress each medial rectus, or depress medial rectus, elevate ipsilateral lateral rectus

'A' exotropia-depress each lateral rectus, or depress lateral rectus, elevate ipsilateral medial rectus

'V' exotropia-elevate each lateral rectus, or elevate lateral rectus, depress ipsilateral medial rectus

Having done this we reviewed a group of 34 children in whom the data was sufficient for detailed retrospective analysis. Eighteen children had enough vertical incomitance to warrant surgical correction and 16 had a major vertical component to their predominantly horizontal strabismus.

\section{Results}

Vertical transposition of the horizontal recti of one eye by $10 \mathrm{~mm}$ (taken to be equivalent to a full muscle width transposition-FMWE) was modelled by the computer as producing 14 to 16 prism dioptres of hypertropia or hypotropia. Our analysis of the 16 children undergoing such a procedure (Tables I and II) reveals a mean correction of 15.6 dioptres of height for FMWE transposition. Perhaps more importantly, 11 of the 16 (69 per cent) achieved an effect of between 15 and 25 prism dioptres, indicating that the procedure is relatively reliable in its effect.

In patients with vertical incomitance the model predicted that appropriate bilateral surgery, transposing the insertions $10 \mathrm{~mm}$, would correct approximately 16 prism
Table II Analysis of surgical results

Hypertropia/Hypotropia

Mean correction-15.6 PD FMWE

Range-8-30 PD

11/16 patients corrected between 15 and 15 PD

$\mathrm{PD}=$ Prism dioptre .

FMWE $=$ Full muscle width equivalent

Table III Analysis of surgical results

\begin{tabular}{lcl}
\hline Type Dev'n & No. & Success/Failure \\
\hline $\begin{array}{l}\text { Bilateral surgery } \\
\text { 'V' eso }\end{array}$ & 8 & \\
'A' eso & 1 & 1 Eliminated \\
'A' exo & 1 & 1 Improved \\
Unilateral surgery & & \\
'V' exo & 8 & 3 Eliminated \\
& & 3 Improved \\
& & 2 Unchanged \\
\hline
\end{tabular}

dioptres of ' $A$ ' or ' $V$ ' with a rather greater effect resulting from lateral rectus transposition. Uniocular surgery, again transposing the insertions $10 \mathrm{~mm}$, corrects rather less vertical incomitance, approximately 12 prism dioptres. The model further predicted that whilst either procedure would induce some torsion, the absolute value would be less than 3 degrees, and unlikely to be of clinical significance.

Table I and Table III show the details of the children treated, and reveal results in accordance with the prediction. All children undergoing bilateral surgery had their ' $A$ ' or ' $V$ ' eliminated or greatly improved, whilst the 8 children with ' $\mathrm{V}$ ' exotropia who had unilateral surgery fared less well.

\section{Discussion}

In this group of children transposition surgery has proved reliable and predictable with no instances of gross overcorrection. Other authors ${ }^{11}$ have found a similarly predictable performance from transposition surgery, and 
though the absolute values of correction varied in different reports our results are comparable to those previously reported. ${ }^{12,13,14,15}$ Unlike one previous author ${ }^{11}$ we have found the response to surgery to be roughly linear with no increase in effectivity when operating on larger deviations. Furthermore, we have found no difference in the horizontal correction achieved with recession or resection procedures when they are combined with transposition of the insertions.

Perhaps the most encouraging feature of this study is the close correlation between the computer prediction of the results of surgery, and actual results obtained. The Clements model is a modification of Robinson's model described in $1975^{16}$ and is largely mechanical in concept. Though based on a number of more or less valid assumptions, it is none the less a most useful guide to thinking about normal and disordered eye movements. That it should so accurately predict the results of certain types of surgery is one hopes, a testimony to its validity, and certainly further development might well aid in improving our management of concomitant childhood strabismus.

\section{Conclusion}

Vertical transposition of the horizontal recti provides a predictable alternative to vertical muscle surgery in those children with both horizontal and vertical deviations, or in children with significant vertical incomitance. The surgeon can anticipate correction of between 15 and 25 prism dioptres of height for full width transposition of both horizontal recti in one eye.

We gratefully acknowledge the help of Dr. Richard Clements in allowing us to use his model and arranging that the Aston University computer be available to produce predictions.

\section{References}

1 Jensen EDF: Rectus muscle union: A new operation for paralysis of the lateral rectus muscles. Trans Pac Coast Oto-Ophthalmol Soc 1964, 45: 359-87.

${ }^{2}$ Harada $M$ and Ito $Y$ : Surgical correction of cyclotropia. Jap J Ophthalmol 1964, 8: 88-96.

${ }^{3}$ Knapp P: Surgical treatment of double elevator paralysis. Trans Am Ophthalmol Soc 1969, 67: 304-23.

${ }^{4}$ Lee JP and Collin JRO: Elevating the hypotropic globe. Br J Ophthalmol 1986, 70: 26-32.

${ }^{5}$ Saunders RA and Rogers GL: Superior oblique transposition for third nerve palsy. Ophthalmol 1982, 89: 310-16.

${ }^{6}$ Elliot RL and Nankin ST: Anterior transposition of the inferior oblique. J Paed Ophthalmol and Strab 1981, 18: 35-8.

${ }^{7}$ Callahan M: Surgically mismanaged ptosis associated with double elevator palsy. Arch Ophthalmol 1981, 99: 108-12.

${ }^{8}$ Dunlap EA: Vertical displacement of the horizontal recti. In: Trans New Orleans Acad Ophthal, Symposium on Strabismus, 1971, St Louis, Mosby, pp 307-29.

${ }^{9}$ Clement RA: Computer simulation of extraocular muscle co-operation: an evaluation. Ophthalmol Physiol Optics 1982, 2: 107-17.

${ }^{10}$ Clement RA and Howrie A: Computer modelling of the muscular factors involved in the aetiology of A and V syndromes. Br Orthop J 1985, 42: 65-8.

${ }^{11}$ Metz HS: Rectus muscle transposition surgery. $J$ Paed Ophthalmol and Strab 1981, 18: 51-4.

12 Foster $J$ and Pemberton EC: The effect of operative alterations in the height of the external rectus insertion. Br J Ophthalmol 1946, 30: 88-92.

13 Alvaro M: Simultaneous correction of vertical and horizontal deviations. Ophthalmologica 1950, 120: $191-7$.

${ }^{14}$ Jones ST: Treatment of hypertropia by vertical displacement of the horizontal recti. Am Orthop J 1977, 27: 107-10.

${ }^{15}$ Burian $H$ and Von Noorden GK: In: Binocular vision and ocular motility Ed. 2 St Louis, CV Mosby Co, 1980, pp 330-476.

${ }^{16}$ Robinson DA: A quantitative analysis of extraocular muscle co-operation and squint. Invest Ophthalmol 1975, 14: 801-25. 